\title{
Population Attributable fraction Estimation of the Cardiovascular Diseases-related factors: An Evidence from western part of Iran
}

\section{Zhila Javani}

Kermanshah University of Medical Sciences

\section{Yahya Salimi}

Kermanshah University of Medical Sciences

\section{Mahdi Moradinazar}

Kermanshah University of Medical Sciences

\section{Farid Najafi ( $\square$ fnajafi@kums.ac.ir)}

Kermanshah University of Medical Sciences https://orcid.org/0000-0002-0819-4730

\section{Research article}

Keywords: Cardiovascular diseases, Risk factors, population attributable fraction, sequential population attributable fraction, average population attributable fraction

Posted Date: January 14th, 2020

DOI: https://doi.org/10.21203/rs.2.20832/v1

License: (c) (i) This work is licensed under a Creative Commons Attribution 4.0 International License. Read Full License 


\section{Abstract}

Background: Cardiovascular diseases are the first cause of deaths and years of lost life due to disability, worldwide. The population attributable fraction has been widely used in literature to quantify an impact of removing risk factors in occurrence of diseases. This study was designed to estimate the population attributable fraction of prevalent cases of cardiovascular diseases associated with different risk factors, using data from people aged 35-65 years old in Ravansar County.

Methods: Data of this study came from 9825 adults aged 35-65 years that were included in the study of Ravansar Non-Communicable disease (RaNCD). First, to identify the confounding variables, we did a comprehensive review of the available resources and then presented the relationship between different risk factors with directed acyclic graphs and for any risk factor. Sequential and average adjusted attributable fractions were used. To calculate $95 \%$ confidence intervals, the Monte Carlo simulation was conducted. All statistical analyses were performed using the 'averisk' package in R version 3.4.4.

Results: The age adjusted prevalence for cardiovascular diseases was 12.6\% (95\% Cl: 11.9, 13.2\%). Among the modifiable predictors of cardiovascular diseases, the highest amount of population attributable fraction after adjusting for age, sex, and other factors associated with cardiovascular diseases, in men were for hypertension 35.7\% (95\% Cl: 30.2, 40.6\%), dyslipidemia 12.2\% (95\% Cl: 7.5, 17.6\%), general obesity 5.7\% (95\% Cl: $-0.7,11.9 \%)$ and for cigarette smoking $4.0 \%$ (95\% Cl: $-6.3,14.6 \%)$, and in women were hypertension $42.8 \%$ (95\% Cl: 36.5, 47.3\%), general obesity 10.7\% (95\% Cl: 6.2, 15.3\%), central obesity $10.1 \%$ (95\% Cl: $-7.0,23.8 \%)$ and for dyslipidemia $9.7 \%$ (95\% Cl: 5.1, 14.5\%).

Conclusion: Due to the difference in the population attributable fraction of cardiovascular diseasesrelated factors in men and women, it is advisable to prioritize preventive cardiovascular diseases interventions by sex segregation. Special attention should be paid to control hypertension, dyslipidemia in men, and hypertension, general obesity and dyslipidemia in women, and priority should be given to strategies for preventing cardiovascular diseases.

\section{Background}

Cardiovascular diseases (CVDs) are the first cause of death and disability- adjusted life years, worldwide [1]. According to the World Health Organization the annual death rate for CVD in 2016 was 17. 9 million people, worldwide[2]. It is anticipated that, by $2020 \mathrm{CVD}$ remains the leading cause of death and disability around the world [3]. In addition, $37 \%$ of all deaths [2] and $80 \%$ of the global burden of CVD are happening in developing countries, and this trend is still on the rise [4]. In Iran, due to the reduction in mortality due to infectious diseases, CVD with 39.3\%, are the first cause of death, of which $19.5 \%$ are related to heart attack, $9.3 \%$ to stroke $3.1 \%$ of high blood pressure, and the rest of it is related to other CVDs [5]. CVD risk factors are divided into two categories of unmodifiable, and modifiable risk factors $[6,7]$.

Despite the high prevalence of CVD and the extent of the associated consequences in developing countries, proper management is not yet applied [4]. The major contributor to the increase of CVDs in 
developing countries is due to an increase in the prevalence of risk factors, and lack of appropriate interventions [8].

The population attributable fraction has been widely used in literature to quantify an impact of removing risk factors in occurrence of diseases [9]. PAF is a proportion of the disease in the population that can potentially be prevented, if the exposure to the risk factor is eliminated [10]. Due to the existing methodological challenges, PAF has been less used as a common public health measure yet; because, most of the procedures used for the calculation of PAF, may produce unsatisfactory data. For example, the contribution of risk factors may sum up to more than $100 \%$ which is unconvincing [11]. Accordingly, some recent studies have addressed the need for new methods of computing PAF $[12,13]$. However, in observational data, estimating the average population attributable fraction using direct method is more promising than other existing methods of adjusted PAF calculation [13]. Accordingly, for PAF calculations in the recent studies, this new approach is used $[12,13]$. The aim of this study was to determine the PAFs of CVD- related factors in Ravansar.

Methods:

\section{Methods}

\section{Study population}

For this study, data came from the baseline of the Ravansar Non-Communicable disease (RaNCD) cohort study. In RaNCD cohort study 10065 individuals aged 35-65 years were included, of which after clearing the data, 9825 (97.6\%) were finally incorporated into this study. RaNCD is one of the 19 centers designed to study the prevalence and incidence of non-communicable diseases, including CVD, in the form of a large and nationwide prospective epidemiologic research studies in Iran (PERSIAN). The first phase of the study began in November 2014. Details of this study has been published elsewhere $[14,15]$.

\section{The study variables}

In this study, following the review of available literature and the expert opinions, the risk factors for CVD were identified [6, 7]. Age was divided into 2 groups; $\geq 45$ and $\geq 55$ years for males and females as high- risk age, and less than 45 and 55 years for male and females as low-risk age [16]. For cigarette smoking, those who used to smoke 100 cigarettes or more in the past or in the present were considered as smokers. Following self-reported variables, the marital status (single/ married), job status (unemployed/ employed), education status (illiterate/ literate (elementary and higher)), the use of hormone replacement therapy, contraceptive pills, menopause, substance abuse, alcohol consumption, family history of CVDs, and the area of residence, were used in analysis. In this study, dyslipidemia was defined as people who have one or more of the following; cholesterol $\geq 240 \mathrm{mg} / \mathrm{dl}$, triglyceride $\geq 200$ $\mathrm{mg} / \mathrm{dl}$, low-density lipoprotein $\geq 160 \mathrm{mg} / \mathrm{dl}$, high-density lipoprotein $\leq 40 \mathrm{mg} / \mathrm{dl}$ and/ or people who used lipid- lowering drugs $[16,17]$. Hypertension also defined as systolic blood pressure $\geq 140 \mathrm{mmHg}$ and/ or diastolic blood pressure $\geq 90 \mathrm{mmHg}$ or use of lowering blood pressure medication $[16,18]$. 
People with fasting blood sugar $\geq 126 \mathrm{mg} / \mathrm{dl}$ and/ or those who consumed anti- diabetic drugs were referred to as diabetic individuals $[19,20]$. Individuals with $\mathrm{BMI} \geq 30$ were considered as obese [18]. The waist to hip ratio $($ WHR $) \geq 0.95$ in males, and $\geq 0.90$ in women was considered as cut off for central obesity [21]. Depression was defined according to a person's self-report and/ or doctor's diagnosis and/ or use of anti- depressants. Physical activity data were collected, using a standard questionnaire. The physical activity level was calculated as MET h/ wk [22]. Subjects were then divided into two groups: light activity (MET < 40) and heavy (MET $\geq 40$ ), based on their physical activity. The socioeconomic status was calculated, based on durable goods. For the study population, using PCA [23]. For the purpose of this study, CVD defined as having ischemic heart disease, myocardial infarction and stroke, by self-report and/ or related drug use [24].

\section{Data analysis}

First, in order to identify the confounding variables, a comprehensive review of literature was conducted. Using current knowledge, several directed acyclic graphs (DAGs) was used to determine covariate adjustment sets for relationship of each risk factors and CVD. Figure 1, shows an example of DAG developed for association between WHR and CVD. In appendix 1, we presented the DAG for other risk factors.

For any risk factor, Sequential and average adjusted attributable fractions were used. To calculate $95 \%$ confidence intervals, the Monte Carlo simulation was conducted. in terms of the theoretical expression comprises the following steps:

1. The risk factor has to be expressed in two distinct categories; in addition, the risk factor has to be eliminated from the study population, regardless of the real status of the subjects, by categorizing all as unexposed.

2. A logistic model has been applied, using this modified dataset in order to estimate the anticipated probabilities for each subject.

3. The total of all anticipated probabilities is the adjusted number of cases of the disease that would be expected if the absence of risk factors in the study population.

4. Then, the AF is equal to the expected cases minus the observed cases, divided by the observed cases.

Any dichotomous risk factor used in the logistic regression model undergoes the same procedure. This is also applied for a sequential attributable fraction, which is the case of sequential elimination of the risk factor of the model. This process is repeated for all possible sequences of exit risk factors from the regression model, and the average estimated values of PAF are considered as the average PAF of the desired risk factor (average PAF). This procedure is named "average attributable fraction" by Eide and Gefeller [12]. 
To calculate $95 \%$ confidence intervals, the Monte Carlo simulation was conducted. All statistical analyses were performed using the 'averisk' package [25] in R version 3.4.4.

\section{Results}

Of the 9825 cases, 4656 (47.4\%) were male and 5169 (52.6\%) were female. About 1333 (13.6\%) were affected by CVD; of which, $468(10.0 \%)$ were male and $865(16.7 \%)$ were female. The mean and standard deviations of the age in participants with CVD were $60.3(\mathrm{SD}=48.9)$ years in both sexes. The findings of this study showed that the adjusted prevalence of CVD was $8.4 \%(95 \% \mathrm{Cl}: 7.5,9.3 \%)$, and $15.2 \%(95 \% \mathrm{Cl}$ : $14.2,16.2 \%$ ), in men and women, respectively (Table 1 ).

The most common modifiable risk factor for CVD was hyperlipidemia (53.2\%) in men $\geq 45$ years and central obesity in women $\geq 55$ years $(89.9 \%)$. The lowest prevalence of modifiable risk factor of CVD was depression in men $\geq 45$ years $(2.4 \%)$ and use of hormone replacement therapy in women $\geq 55$ years (0.7\%), (Table 1).

Among the modifiable predictors of cardiovascular diseases, the highest amount of population attributable fraction after adjusting for age, sex, and other factors associated with CVD, in males were for hypertension $35.7 \%$ (95\% Cl: 30.2, 40.6), dyslipidemia 12.2\% (95\% Cl: 7.5, 17.6), general obesity $5.7 \%$ (95\% Cl: $-0.7,11.9)$ and for cigarette smoking $4.0 \%(95 \% \mathrm{Cl}:-6.3,14.6)$, and in females were hypertension $42.8 \%$ (95\% Cl: $36.5,47.3)$, general obesity $10.7 \%$ (95\% Cl: $6.3,15.3)$, central obesity $10.1 \%$ (95\% Cl: -7.0 , 23.8) and for dyslipidemia $9.7 \%(95 \% \mathrm{Cl}: 5.1,14.5)$. In terms of numerical value, the total PAF attributed to the total number of CVD was higher in women, compared to men. The PAF to the total CVD was $93.4 \%$ and $97.7 \%$, in men and women, respectively (Table2).

The PAF comparison for each gender- specific risk factor is shown in figure 2, which illustrates how the PAFs differ in the CVD- associated risk in men and women. The most differences in adjusted PAF for WHR, 6.8 units was observed between men and women (Figure 2)

\section{Discussion}

The association between classic risk factors and CVD has been proven, but even for those risk factors with the same effect size, they can produce a completely different effect on the occurrence of disease due to the difference in the prevalence, so the calculation of PAF must be performed, using the population of the target community.

Comparison of the results of PAF studies in different societies might be difficult. In fact, different reports have used different demographic groups, in terms of gender, age and ethnicity. In addition, different set of risk factors for calculation of PAF might be entered to the model and also different computational methods are used with different definitions and cut- off points for risk factors. Therefore, such variations create major difference in the PAF values of the risk factors [13], which makes it difficult to compare the results of such studies. 
In the present study, PAF of hypertension for CVDs has a higher value in women (42.8\%) than in men (35.7\%), and this difference has been reported from two population based cohort studies conducted in Iran (19.3\% in women vs. $11.7 \%$ in men) and (17\% in women vs. $9.4 \%$ in men) [26, 27]. Also, it is consistent with the results of study in Sweden from "the Malmö preventive project" (23\% in women vs. $12 \%$ in men) [28]. However, PAF of hypertension for CVD has a lower ranking in report of study in Sweden compared to other risk factors [28]. In addition, in a study conducted in Germany using health and nutrition survey data [12], the highest PAF was related to hypertension. However, the ranking for other risk factors is different.

Our results indicated the prevalence of dyslipidemia was higher in men (53.2\%) than in women (46.7\%), which is in line with the findings of another population-based cohort study in Iran (22.5\% in men vs. $33.2 \%$ in women) [26] and a report from Denmark (47\% in men vs. $57 \%$ in women) [29]. In the present study, the PAF of dyslipidemia for developing CVD was higher in men (12.2\%) than in women $(9.7 \%)$, which is in contrast with the findings from elsewhere (36\% in men vs. $46.5 \%$ in women in Latin America and $18 \%$ in men vs. $23 \%$ in women in Sweden) $[28,30]$. It is similar to the study that was conducted in Argentina and the United States reported that the PAF of dyslipidemia in both groups $(16.0 \%$ in men vs. $15.6 \%$ in women) gained the third ranking for CVD disease [31], which is consistent with the results of the current study in terms of ranking. However, in the present study dyslipidemia made higher contribution to the prevalence of cases with CVD among men compared to women. This difference might be due to different demographic characteristics of the study sample and different definition of dyslipidemia compared to the present study.

In the present study, the prevalence of diabetes was higher in men $(11.4 \%)$ than in women(4.2\%), which is in line with the results of the study in Denmark (4\% in men vs. $2 \%$ in women) [29] and Spain $(11.7 \%$ in men vs. $8.4 \%$ in women) [32], but in contrast with the findings of another study in Iran (14.4\% in men vs. $15.9 \%$ in women) [26]. In addition, the results of this study showed that PAF of diabetes, for developing CVD is higher in women (3.9\%) than men (3.8\%), which is consistent with the results of studies conducted in industrialized countries, showing a greater impact of diabetes on the incidence of CVD in women population [33]. While PAF of diabetes was reported twice in women, compared to men (6\% versus $3 \%)$ in Sweden [28], in Spain a significant difference was observed in women (16.2\%) compared to men (1.7\%) [32].

In our study, while, general obesity was not statistically significantly contributed to the prevalence of CVDs among men, almost (16.7\%) of CVD in RaNCD was due to BMI $\geq 30$. In addition, PAF of general obesity for CVD was more in women (10.7\%) compare to men (5.7\%). Due to different cut- off points and differences in computational methods, the results of this study were not consistent with the study in Denmark (7\% in women vs. $10 \%$ in men) and Spanish population (36.5\% in women vs. $42.5 \%$ in men) [29, 32]. On the other hand, central obesity (WHR) independent of general obesity (BMI), was the risk factor of occurrence of CVD [34]. In the present study, although none statistically significantly, PAF of central obesity, for developing CVD is more in women (10.1\%), than in men (3.3\%). The differences between men 
and women is consistent with the study of "Interheart Latin American" (63.1\% in women vs. $35.8 \%$ in men) and other reports from Iran (9.9\% in women vs. $5.9 \%$ in men) $[26,30]$.

Moreover, the prevalence of depression was higher in women (3.7\%) than in men (2.4\%). Not surprisingly, in the current study, the PAF of depression for developing CVD was higher in women (4.4\%) than in men (3.1\%), which is in agreement with the results of the study of "Interheart Latin American" (1.4\% in women vs. $5.3 \%$ in men) [30]. This contradiction might be due to the differing demographic characteristics of the studied population and different definitions of depression.

The findings of this study showed that PAF of cigarette smoking in developing CVD in men (4.0\%) is more than women (1.3\%), which is consistent with the results of the study conducted in Argentina and the United States (10.1\% in men vs. $7.2 \%$ in women) and Spain (33.9\% in men vs. $8 \%$ in women) [31, 32]. It is also consistent with the results of the study of "Interheart Latin American" (42.5\% in men vs. $25.7 \%$ in women) [30], but due to the higher prevalence of smoking in both sexes in Western countries, the findings of ours differ from those of other countries. In fact, the definition of smoking in our study might be different from others in which current smokers are those who have smoked at least 100 cigarettes during his/ her life. Such definition, although increases the prevalence of smoking, dilutes the effect size and therefore such points need to take into consideration for any interpretation of PAF related to smoking.

the results showed the prevalence of physical inactivity was higher in women (68.2\%) than in men (51.3\%), which is in line with the results of population-based cohort study in Iran (62.9\% in women vs. $65.6 \%$ in men) [26] and of study in Denmark (19\% in women vs. $20 \%$ in men) [29]. Further, the PAF of physical inactivity for developing CVD was higher in men (1.8\%) than in women (1.3\%), which is in agreement with the results of the "Interheart Latin American study" (28.1\% in men vs. $27.9 \%$ in women) [30], and in contrast with the findings of study in Denmark ( $5 \%$ in men vs. $7 \%$ in women) [29]. In fact, PAF of physical inactivity (compared to other risk factors) in other studies is higher than the present study. This might be due to the use of different demographic groups, different computational methods, and ultimately different definitions and cut-off points for included variables.

The prevalence of alcohol consumption was lower in women $(0.0 \%)$ than in men $(10.8 \%)$, which is consistent with the similar study conducted in Sweden (10\% in women vs. $32 \%$ in men) [28] but contradicting the findings of the study in Denmark (88\% in women vs. $56 \%$ in men) [29]. In the present study, alcohol consumption in women (-0.1) has lower PAF, compared to men (1.9), which is consistent with the results of the study in Sweden ( $1 \%$ in women vs. $3 \%$ in men) and Denmark ( $-1 \%$ in women vs. $12 \%$ in men) $[28,29]$. This difference can be due to low prevalence of alcohol use in the included population in RaNCD plus different definitions and cut-off points considered for this variable within all above mentioned studies. The results of this study were not in line with Interheart study in Latin American [30].

The findings of this study showed no significant statistical relationships between the CVD and substance abuse, occupation, place of residence, taking contraceptive pills, the use of hormone replacement therapy and menopause. None of the previous studies looked at these variables [26-33]. 
The PAF of socioeconomic status was low for CVD. It was higher in men (6.7\%) than in women (3.8\%), which is not consistent with the results of the study conducted in Denmark $(10 \%$ in men vs. $15 \%$ in women) [29], this difference is probably due to the use of different demographic groups, different computational methods, and ultimately different definitions and cut-off points for included variables.

In the present study, high-risk age in men (15.0\%), in comparison with women (6.3\%) had a higher PAF, which was consistent with the results of two population based cohort studies conducted in Iran $(36.1 \%$ in men vs. $16.6 \%$ in women and $42 \%$ in men vs. $22 \%$ in women) $[26,27]$ and a study from China $(11.4 \%)$ [12].

The family history of CVD, in the presence of other variables, had a higher PAF in men (1.5\%), compared to women $(0.7 \%)$, which was not statistically significant in both genders. The results of this study are consistent with the results of the study from Sweden ( $9 \%$ in men vs. $3 \%$ in women) [28], but different from the results of two population based cohort studies conducted in Iran (3.9\% in men vs. $7.6 \%$ in women and $2.5 \%$ in men vs. $6.8 \%$ in women) [26, 27]; This difference is partly due to inclusion of different population.

In interpreting the results of studies on PAF, it should be considered that the reduction in the incidence of disease attributed to each risk factor is a theoretical concept. Because in practice, one can never reduce the exposure to a risk factor to zero in the community, or no one can design an intervention that, while maintaining the exposure to other risk factors, affects only one particular risk factor [35]. As a result, PAF values are more appropriate to prioritize the impact of risk factors at the community level, rather than planning, to achieve practically, this level of reductions.

Study Strength and Limitations

For the purpose of this study we used the prevalent cases. Thus, due to lack of knowledge regarding exposure-outcome associations of individuals in such studies, the identification of temporality between exposure and outcome is difficult. Therefore we cannot discuss about causality. Despite these limitations, there are several strengths in current study that are including use of population-based Information; large sample size, and high quality data. In addition, the accuracy of PAF estimation is dependent on the correct detection of confounders of each risk factor, so the directed acyclic graph was used.

\section{Conclusion}

Given the difference in the PAF's ranking of risk factors in men and women, prioritizing gender-specific preventive CVD interventions are recommended. In this regard, special attention should be paid to the control of high blood pressure, dyslipidemia, in men, and high blood pressure, general obesity, and dyslipidemia in women. Our results from a community based study provide necessary information needed to achieve the maximum reduction in the prevalence of CVD in the community through appropriate interventions based on indigenous evidence of the Country.

\section{Abbreviations}


CVD: Cardiovascular diseases; RaNCD: Ravansar Non-Communicable disease; PAF: Population attributable fraction; BMl: Body mass index; WHR: Waist to hip ratio; MET: Metabolic equivalent of task; PCA: Principal component analysis; DAG: Directed acyclic graph; SD: Standard Deviation; SES: Socioeconomic status; OCP: Oral contraceptive pill; HRT: Hormone replacement therapy

\section{Declarations}

\section{Acknowledgments}

RaNCD is part of the PERSIAN national cohort and we would like to thank Professor Reza Malekzadeh, Deputy of Research and Technology at the Ministry of Health and Medical Education of Iran and Director of the PERSIAN cohort and also Dr. Hussein Postiche, Executive Director of PERSIAN cohort for all their supports for design and performing RaNCD.

\section{Authors' contributions}

ZJ conceived and designed the study and drafted the manuscript. YS helped in designing the study, data analysis and editing manuscript. MM helped in the study, collecting data, and editing manuscript. FN helped in editing the manuscript. All authors involved in the making of this manuscript have read and approved the finalized version.

\section{Funding}

No financial support was received for this research.

\section{Availability of data and materials}

Upon request, we can offer onsite access to external researchers to the data analyzed at Kermanshah University of Medical Sciences, Iran. To do so, Dr. Najafi should be contacted.

\section{Ethics approval and consent to participate}

All participants were informed about the study and confidentiality protocols. Written Informed consent was obtained from all the participants. This study was supported by Kermanshah University of Medical Sciences (Grant No: 92472). The cohort study was approved by the Ethics Committee of Kermanshah University of Medical Sciences (ethics approval number: KUMS.REC.1394.318).

\section{Consent for publication}

Not applicable.

\section{Competing interests}

The authors declare that they have no competing interests. 


\section{References}

1. Lozano R, Naghavi M, Foreman K, Lim S, Shibuya K, Aboyans V, Abraham J, Adair T, Aggarwal R, Ahn SY: Global and regional mortality from 235 causes of death for 20 age groups in 1990 and 2010: a systematic analysis for the Global Burden of Disease Study 2010. The lancet 2012, 380(9859):20952128.

2. Cardiovascular diseases (CVDs)Fact sheet [http://www.who.int/mediacentre/factsheets/fs317/en/]

3. Murray CJ, Lopez AD: Mortality by cause for eight regions of the world: Global Burden of Disease Study. The lancet 1997, 349(9061):1269-1276.

4. Kabagambe EK, Baylin A, Campos H: Nonfatal acute myocardial infarction in Costa Rica: modifiable risk factors, population-attributable risks, and adherence to dietary guidelines. Circulation 2007, 115(9):1075-1081.

5. Davarani R, Robati N: Cardiovascular Diseases Risk Factors and the Relationship between Knowledge Level and Preventive Behaviors for Cardiovascular Diseases among Women in Kerman. Health-Based Research.

6. Dawber TR, Meadors GF, Moore Jr FE: Epidemiological approaches to heart disease: the Framingham Study. American Journal of Public Health and the Nations Health 1951, 41(3):279-286.

7. Keys A, Mienotti A, Karvonen MJ, Aravanis C, Blackburn H, Buzina R, Djordjevic B, Dontas A, Fidanza $\mathrm{F}$, Keys $\mathrm{MH}$ : The diet and 15-year death rate in the seven countries study. American journal of epidemiology 1986, 124(6):903-915.

8. Gaziano TA: Reducing the growing burden of cardiovascular disease in the developing world. Health affairs 2007, 26(1):13-24.

9. Qiu H, Yu I: Making nomogram to estimate the population attributable fraction. Zhonghua liu xing bing xue za zhi= Zhonghua liuxingbingxue zazhi 2008, 29(1):75-77.

10. Rockhill B, Newman B, Weinberg C: Use and misuse of population attributable fractions. American journal of public health 1998, 88(1):15-19.

11. Rowe AK, Powell KE, Flanders WD: Why population attributable fractions can sum to more than one. American journal of preventive medicine 2004, 26(3):243-249.

12. Rückinger $S$, von Kries $R$, Toschke AM: An illustration of and programs estimating attributable fractions in large scale surveys considering multiple risk factors. $B M C$ medical research methodology 2009, 9(1):7.

13. Mason CA, Tu S: Partitioning the population attributable fraction for a sequential chain of effects. Epidemiologic Perspectives \& Innovations 2008, 5(1):5.

14. Eghtesad S, Mohammadi Z, Shayanrad A, Faramarzi E, Joukar F, Hamzeh B, Farjam M, Sakhvidi MJZ, Miri-Monjar M, Moosazadeh M: The PERSIAN cohort: providing the evidence needed for healthcare reform. Archives of Iranian medicine 2017, 20(11):691.

15. Poustchi H, Eghtesad S, Kamangar F, Etemadi A, Keshtkar A-A, Hekmatdoost A, Mohammadi Z, Mahmoudi Z, Shayanrad A, Roozafzai F: Prospective epidemiological research studies in Iran (the 
PERSIAN Cohort Study): Rationale, objectives, and design. American journal of epidemiology 2017, 187(4):647-655.

16. Lorenzo C, Williams K, Hunt KJ, Haffner SM: The National Cholesterol Education Program-Adult Treatment Panel III, International Diabetes Federation, and World Health Organization definitions of the metabolic syndrome as predictors of incident cardiovascular disease and diabetes. Diabetes care 2007, 30(1):8-13.

17. Chu F-L, Hsu C-H, Jeng C: Lowered cutoff points of obesity indicators are better predictors of hypertension and diabetes mellitus in premenopausal Taiwanese women. Obesity research \& clinical practice 2015, 9(4):328-335.

18. Samavat T, Hojatzadeh E, ShamsM AA, Mahdavi A, Bashti S: Methods of prevention and control CardioVascular Disease. In.: Tehran: Mehravesh; 2013.

19. Association AD: Standards of medical care in diabetes-2015 abridged for primary care providers. Clinical diabetes: a publication of the American Diabetes Association 2015, 33(2):97.

20. Genuth S, Alberti K, Bennett P, Buse J, DeFronzo R, Kahn R, Kitzmiller J, Knowler WC, Lebovitz H, Lernmark A: Follow-up report on the diagnosis of diabetes mellitus. Diabetes care 2003, 26(11):31603168.

21. Hadaegh F, Zabetian A, Sarbakhsh P, Khalili D, James W, Azizi F: Appropriate cutoff values of anthropometric variables to predict cardiovascular outcomes: 7.6 years follow-up in an Iranian population. International journal of obesity 2009, 33(12):1437.

22. Ainsworth BE, Haskell WL, Whitt MC, Irwin ML, Swartz AM, Strath SJ, O Brien WL, Bassett DR, Schmitz KH, Emplaincourt PO: Compendium of physical activities: an update of activity codes and MET intensities. Medicine and science in sports and exercise 2000, 32(9; SUPP/1):S498-S504.

23. Jolliffe I: Principal component analysis: Springer; 2011.

24. Benjamin I, Griggs RC, Wing EJ, Fitz JG: Andreoli and Carpenter's Cecil Essentials of Medicine EBook: Elsevier Health Sciences; 2015.

25. Ferguson J, Alvarez-Iglesias A, Newell J, Hinde J, O’Donnell M: Estimating average attributable fractions with confidence intervals for cohort and case-control studies. Statistical methods in medical research 2018, 27(4):1141-1152.

26. Azimi SS, Khalili D, Hadaegh F, Yavari P, Mehrabi Y, Azizi F: Calculating population attributable fraction for cardiovascular risk factors using different methods in a population based cohort study. Journal of research in health sciences 2014, 15(1):22-27.

27. Khalili D, Sheikholeslami FH, Bakhtiyari M, Azizi F, Momenan AA, Hadaegh F: The incidence of coronary heart disease and the population attributable fraction of its risk factors in Tehran: a 10-year population-based cohort study. PloS one 2014, 9(8):e105804.

28. Nilsson P, Nilsson JÅ, Berglund G: Population-attributable risk of coronary heart disease risk factors during long-term follow-up: the Malmö Preventive Project. Journal of internal medicine 2006, 260(2):134-141. 
29. Schnohr P, Jensen JS, Scharling H, Nordestgaard B: Coronary heart disease risk factors ranked by importance for the individual and community. A 21 year follow-up of 12000 men and women from The Copenhagen City Heart Study. European heart journal 2002, 23(8):620-626.

30. Lanas F, Avezum A, Bautista LE, Diaz R, Luna M, Islam S, Yusuf S: Risk factors for acute myocardial infarction in Latin America: the INTERHEART Latin American study. Circulation 2007, 115(9):10671074.

31. Moran A, DeGennaro V, Ferrante D, Coxson PG, Palmas W, Mejia R, Perez-Stable EJ, Goldman L: Coronary heart disease and stroke attributable to major risk factors is similar in Argentina and the United States: the Coronary Heart Disease Policy Model. International journal of cardiology 2011, 150(3):332-337.

32. Medrano MJ, Pastor-Barriuso R, Boix R, Del Barrio JL, Damián J, Álvarez R, Marín A: Coronary disease risk attributable to cardiovascular risk factors in the Spanish population. Revista espanola de cardiologia 2007, 60(12):1250-1256.

33. Danaei G, Lawes CM, Vander Hoorn S, Murray CJ, Ezzati M: Global and regional mortality from ischaemic heart disease and stroke attributable to higher-than-optimum blood glucose concentration: comparative risk assessment. The Lancet 2006, 368(9548):1651-1659.

34. Haffner S, Despres J, Balkau B, Deanfield J, Barter P, Bassand J, Fox K, Van Gaal L, Wittchen H, Tan C: Waist circumference and Body Mass Index are both independently associated with cardiovascular disease. The International Day for the Evaluation of Abdominal Obesity (IDEA) survey. In: Journal of the American College of Cardiology: 2006: ELSEVIER SCIENCE INC 360 PARK AVE SOUTH, NEW YORK, NY 10010-1710 USA; 2006: 358A-358A.

35. Levine B: Peer Reviewed: What Does the Population Attributable Fraction Mean? Preventing chronic disease 2007, 4(1).

\section{Tables}

Table1. Prevalence of cardiovascular risk factors in RaNCD cohort by gender and age 


\begin{tabular}{|c|c|c|c|c|c|}
\hline \multirow{2}{*}{ Risk factors } & & \multicolumn{2}{|r|}{ Male } & \multicolumn{2}{|c|}{ Female } \\
\hline & & Age $<45$ & Age $\geq 45$ & Age $<55$ & Age $\geq 55$ \\
\hline \multicolumn{2}{|c|}{ Total $\mathbf{N}(\%)$} & $2073(44.5)$ & $2583(55.5)$ & $3913(75.7)$ & $1256(24.3)$ \\
\hline \multirow[t]{2}{*}{ Family history of CVD } & Yes & $414(19.1)$ & $486(18.8)$ & $881(22.5)$ & $258(20.5)$ \\
\hline & No & $1659(80.0)$ & $2097(81.2)$ & $3032(77.5)$ & $998(79.5)$ \\
\hline \multirow[t]{2}{*}{ Socioeconomic status } & Richest & $1353(65.3)$ & $1586(61.4)$ & $1681(42.1)$ & $299(23.8)$ \\
\hline & Poorest & $720(34.7)$ & $997(38.6)$ & $2232(57.0)$ & $957(76.2)$ \\
\hline \multirow{2}{*}{ a smoking } & $\geq 100$ yarns & $605(29.2)$ & $1082(41.9)$ & $89(2.2)$ & $173(13.8)$ \\
\hline & $<100$ yarns & $1468(70.8)$ & 1501(58.1) & $3824(97.7)$ & $1083(86.2)$ \\
\hline \multirow[t]{2}{*}{ Drug abuse } & Yes & $123(5.9)$ & $155(6.0)$ & $7(0.2)$ & $1(0.1)$ \\
\hline & No & $1950(94.0)$ & $2428(94.0)$ & 3906 (99.8) & 1255 (99.9) \\
\hline \multirow[t]{2}{*}{ Alcohol use } & Yes & $340(16.4)$ & $278(10.8)$ & $4(0.1)$ & $0(0.0)$ \\
\hline & No & $1733(83.6)$ & $2305(89.2)$ & 3909 (99.9) & $1256(100.0)$ \\
\hline \multirow[t]{2}{*}{ b Dyslipidemia } & Yes & $1098(52.1)$ & $1373(53.2)$ & $1302(33.2)$ & $587(46.7)$ \\
\hline & No & $975(47.0)$ & $1210(46.8)$ & $261(66.7)$ & $669(53.3)$ \\
\hline \multirow{2}{*}{${ }^{\mathrm{C}}$ Hypertension } & Yes & $89(4.3)$ & $508(19.7)$ & $454(11.6)$ & $490(39.0)$ \\
\hline & No & $1984(95.7)$ & 2075 (80.3) & $3459(88.4)$ & $766(60.1)$ \\
\hline \multirow[t]{2}{*}{$\mathrm{d}_{\text {Diabetes }}$} & Yes & $68(3.3)$ & $295(11.4)$ & $256(6.5)$ & $178(4.2)$ \\
\hline & No & 2005 (96.7) & 2288 (88.6) & 3657 (93.5) & 1078 (85.8) \\
\hline \multirow[t]{2}{*}{ Physical activity } & $<45$ & $1003(48.4)$ & 1325 (51.3) & 2457 (62.8) & $857(68.2)$ \\
\hline & $\geq 45$ & $1070(51.6)$ & $1258(48.7)$ & $1456(37.2)$ & 399 (31.8) \\
\hline \multirow[t]{2}{*}{ Body mass index } & $\geq 30$ & 357 (17.2) & $431(16.7)$ & $1502(38.4)$ & $392(31.2)$ \\
\hline & $<30$ & $1716(82.8)$ & 2152 (83.3) & 2411 (61.6) & $864(68.8)$ \\
\hline \multirow[t]{2}{*}{${ }^{\mathrm{e}}$ Waist hip ratio } & High Risk & $445(21.5)$ & $617(23.9)$ & $3500(89.5)$ & $1129(89.9)$ \\
\hline & Low Risk & 1628 (78.5) & 1966 (76.1) & $413(10.6)$ & $127(10.1)$ \\
\hline \multirow[t]{2}{*}{$\mathrm{f}_{\text {Depression }}$} & Yes & $30(1.5)$ & $63(2.4)$ & $235(6.0)$ & $46(3.7)$ \\
\hline & No & 2043 (98.6) & $2520(97.6)$ & $3678(93.1)$ & $1210(96.3)$ \\
\hline \multirow[t]{2}{*}{ Job } & Unemployed & $9(0.4)$ & $8(0.3)$ & $3157(80.7)$ & 1091 (86.9) \\
\hline & Employed & 2064 (99.6) & 2575 (99.7) & 756 (19.3) & $165(13.1)$ \\
\hline \multirow[t]{2}{*}{ place } & City & $1271(61.3)$ & $1590(61.6)$ & $2288(58.5)$ & $676(53.8)$ \\
\hline & Village & $802(38.7)$ & $993(38.4)$ & 1625 (41.5) & $580(46.2)$ \\
\hline \multirow[t]{2}{*}{ Marital State } & Single & $108(5.21)$ & $22(0.6)$ & $544(13.9)$ & $273(21.7)$ \\
\hline & Married & 1965 (94.8) & 2561 (99.1) & 3369 (86.1) & $983(78.3)$ \\
\hline \multirow[t]{2}{*}{ Education } & illiterate & $44(2.1)$ & $555(21.5)$ & $855(21.9)$ & $958(76.3)$ \\
\hline & Literate & 2029 (97.9) & 2028 (78.5) & 3058 (78.2) & $298(23.7)$ \\
\hline \multirow[t]{2}{*}{ Menopause } & Yes & - & - & $1215(31.1)$ & $405(32.3)$ \\
\hline & No & - & - & $2698(68.1)$ & $851(67.8)$ \\
\hline \multirow[t]{2}{*}{ Use of Oral contraceptive pill } & Yes & - & - & $2964(75.8)$ & $852(67.8)$ \\
\hline & No & - & - & $949(24.3)$ & $404(32.2)$ \\
\hline \multirow{2}{*}{$\begin{array}{l}\text { Use of Hormone replacement } \\
\text { therapy }\end{array}$} & Yes & - & - & $16(0.4)$ & $9(0.7)$ \\
\hline & No & - & - & $3897(99.6)$ & $1247(99.3)$ \\
\hline
\end{tabular}

a Smoking (those who used to smoke 100 cigarettes or more in the past or in the present), $\mathrm{b}$ dyslipidemia: cholesterol $\geq 240 \mathrm{mg} / \mathrm{dl}$, triglyceride $\geq 200 \mathrm{mg} / \mathrm{dl}$, low-density lipoprotein $\geq 160 \mathrm{mg} / \mathrm{dl}$, high-density lipoprotein $\leq 40 \mathrm{mg} / \mathrm{dl}$ or anti-dyslipidemia medication, ${ }^{\mathrm{c}}$ hypertension: systolic blood pressure $\geq 140 \mathrm{mmHg}$ or diastolic blood pressure $\geq 90 \mathrm{mmHg}$ or anti-hypertensive medication, ${ }^{\mathrm{d}}$ diabetes: fasting blood sugar $\geq 126 \mathrm{mg} /$ 
dl or anti-diabetes medication, e central obesity: waist/ hip ratio $\geq 0.95$ for mail and $\geq 0.90$ For female, $f$ depression (Self-report depression and/or anti-depression medication).

Table2. Adjusted attributable fraction to cardiovascular disease in RaNCD cohort by gender

\begin{tabular}{|c|c|c|c|}
\hline \multicolumn{3}{|c|}{ Adjusted attributable fraction, $\%,(95 \%$, confidence interval ) } & \multirow[t]{2}{*}{ Risk Factor } \\
\hline Total & Female & Male & \\
\hline $4.2(-1.4,8.1)$ & $6.3(0.5,128)$ & $15.0(1.7,27.8)$ & a High risk age \\
\hline $1.1(-2.2,4.0)$ & $0.7(-3.7,5.4)$ & $1.5(-2.9,6.8)$ & Family history of CVD \\
\hline $3.5(-1.7,8.9)$ & $3.8(-1.3,8.7)$ & $6.7(-11.7,20.9)$ & Socioeconomic status(low) \\
\hline $4.3(1.1,8.1)$ & $1.3(0.1,2.5)$ & $4.0(-6.3,14.6)$ & b Smoking \\
\hline $0.8(-0.1,1.9)$ & $0.1(-0.1,0.5)$ & $1.9(-0.5,5.3)$ & Drug abuse \\
\hline $0.4(-1.0,1.6)$ & $-0.1(-0.1,0.1)$ & $1.9(-1.3,6.2)$ & Alcohol use \\
\hline $9.3(5.3,13.1)$ & $9.7(5.2,14.5)$ & $12.2(7.5,17.6)$ & ${ }^{\mathrm{C}}$ Dyslipidemia \\
\hline $35.9(32.1,38.1)$ & $42.8(36.6,47.3)$ & $35.7(30.2,40.6)$ & $\mathrm{d}_{\text {Hypertension }}$ \\
\hline $3.6(1.7,5.5)$ & $3.9(2.0,6.0)$ & $3.8(2.1,6.4)$ & e Diabetes \\
\hline $2.7(-4.7,8.7)$ & $1.3(-6.7,8.0)$ & $1.8(-11.8,16.4)$ & Physical inactivity $(<40 \mathrm{Met})$ \\
\hline $7.9(4.8,10.5)$ & $10.7(6.3,15.3)$ & $5.7(-0.7,11.9)$ & Body mass index $(\geq 30)$ \\
\hline $6.9(-3.8,13.7)$ & $10.1(-7.0,23.8)$ & $3.3(-3.8,10.9)$ & $\mathrm{f}_{\text {Waist hip ratio }}$ \\
\hline $4.0(2.1,5.1)$ & $4.4(3.2,6.1)$ & $3.1(1.8,4.5)$ & ${ }^{g}$ Depression \\
\hline $8.8(4.8,12.1)$ & $-5.6(-8.3,6.9)$ & $-0.2(-0.3,0.5)$ & Job(Unemployed) \\
\hline $4.2(-0.3,8.4)$ & $6.9(-0.9,13.1)$ & $-1.9(-11.5,6.0)$ & place(City) \\
\hline$-0.1(-6.1,5.6)$ & $-1.8(-8.5,5.4)$ & $-1.1(-9.1,5.5)$ & Marital State(Single) \\
\hline- & $2.4(-11.3,14.3)$ & - & Has Menopause \\
\hline- & $0.8(-1.1,3.5)$ & - & Use of Oral contraceptive pill \\
\hline- & $0.03(-0.2,0.5)$ & - & Use of Hormone replacement therapy \\
\hline 97.5 & 97.7 & 93.4 & Total \\
\hline
\end{tabular}

a High risk age: male $\geq 45 \mathrm{yr}$ old and female $\geq 55 \mathrm{yr}$ old, ${ }^{\mathrm{b}}$ Smoking (those who used to smoke 100 cigarettes or more in the past or in the present), ${ }^{C}$ dyslipidemia: cholesterol $\geq 240 \mathrm{mg} / \mathrm{dl}$, triglyceride $\geq 200 \mathrm{mg} / \mathrm{dl}$, lowdensity lipoprotein $\geq 160 \mathrm{mg} / \mathrm{dl}$, high-density lipoprotein $\leq 40 \mathrm{mg} / \mathrm{dl}$ or anti-dyslipidemia medication, $\mathrm{d}$ hypertension: systolic blood pressure $\geq 140 \mathrm{mmHg}$ or diastolic blood pressure $\geq 90 \mathrm{mmHg}$ or anti-hypertensive medication, ${ }^{\mathrm{e}}$ diabetes: fasting blood sugar $\geq 126 \mathrm{mg} / \mathrm{dl}$ or anti-diabetes medication, ${ }^{\mathrm{f}}$ central obesity: waist/ hip ratio $\geq 0.95$ for mail and $\geq 0.90$ For female, ${ }^{g}$ depression (Self-report depression and/or anti-depression medication).

\section{Figures}




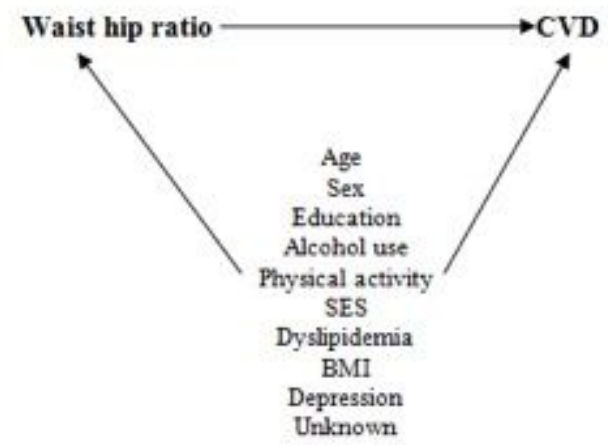

Figure 1

An example of DAG for association between WHR and CVD

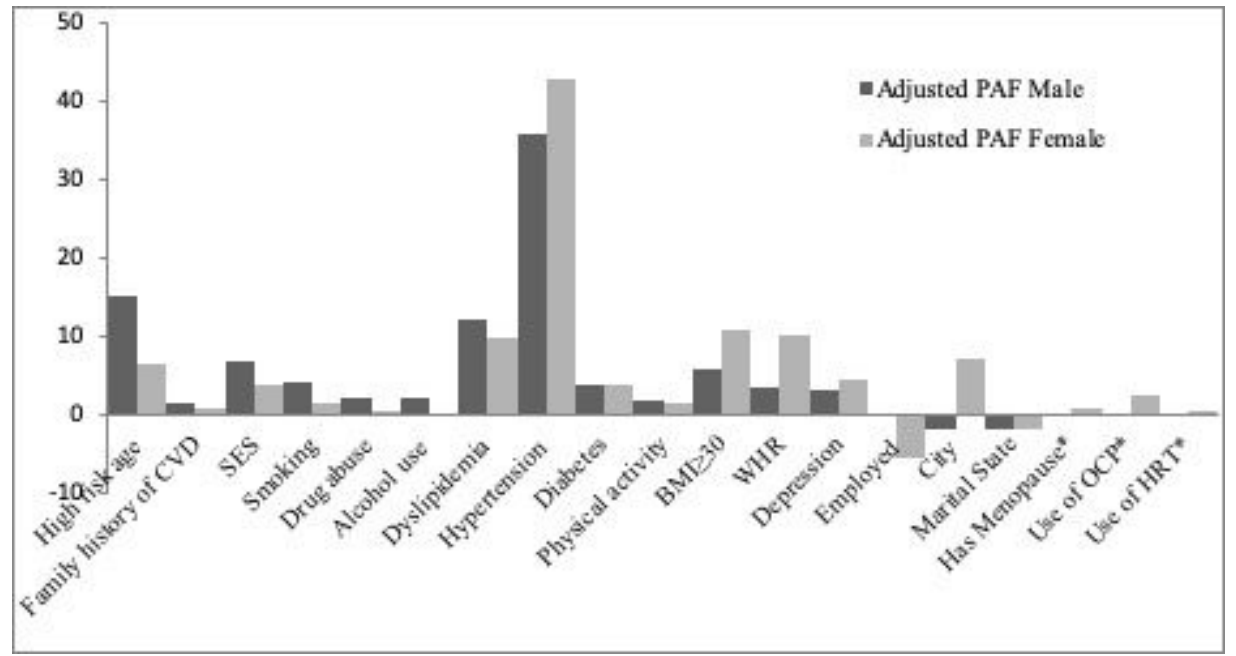

Figure 2

The comparison adjusted PAF of CVD

\section{Supplementary Files}

This is a list of supplementary files associated with this preprint. Click to download.

- Appendix.docx 